\title{
Exploration and Practice of New Curriculum System Construction of Musicology
}

\author{
Ling Yang \\ School of Education \\ Chengdu Normal University \\ Chengdu, China
}

\author{
Shengdong Yue \\ School of Music \\ Chengdu Normal University \\ Chengdu, China
}

\begin{abstract}
Under the background of education reform that calls for music teaching returning to the origin of music, this paper discusses the exploration and practices of curriculum system construction for undergraduate musicology major in Chengdu Normal University. It sheds light on how to combine the sophisticated international education concept with Chinese music culture and education situation, and on the basis, demonstrates how to establish an advanced practical music education system. On the basis of the years of practices on curriculum reform, this paper puts forward a "one center, four simultaneous actions" professional talent training model that is in line with the goal of music teacher training in primary and secondary schools.
\end{abstract}

Keywords—musicology; curriculum system; reform exploration

\section{INTRODUCTION}

Although the music education in teachers' universities of China has undergone hundreds of years' development, its curriculum is still modeled after music college in Paris in the early 19th century. In particular, the music theory, solfeggio, vocal music, piano, harmony, form and other main courses all reflect the dependence of music education in China on the western "emphasis on technology" mode. However, it is difficult to cultivate the school running characteristics on the basis of the higher music education system which is almost "'single", "homogeneous" and "standardized". At present, the music education and academic circles call for equality, dialogue and understanding, and look forward to the integration of music and life. It has never happened before that the Chinese people's faith, the relationship between music and the spiritual world, etc., had aroused our attention and sense of crisis. Much of the attention is now put onto the issues concerning music education like people-orientation, nonintellectual factors, emotional development, personality growth and mental health and so on.

\section{EXPLORING THE COMBINATION OF ADVANCED EDUCATIONAL IDEAS WITH LOCAL MUSIC CULTURE AND EDUCATION PRACTICE}

Under this background, how to train excellent music educators and how to fulfill the "university mission" in cultural inheritance have become problems that must be solved in music education in normal universities. On the one hand, we look forward to returning to our native music culture, so in July 2014, Chengdu Normal University (CNU) established a

Project Fund: Sichuan Education and Research Grant Project "Theory and Practice of New Curriculum System Construction of Musicology” (CJH No. [2018]495) national intangible cultural heritage base "Sichuan Dulcimer" in cooperation with Sichuan Academy of Arts, and set up a team to carry out work led by successors of national and provincial "Sichuan Dulcimer" and "Ballad-singing in Sichuan” in Sichuan and Chongqing, as well as assisted by some of the experts and scholars. At the same time, we have visited various parts of the province many times to collect customs, hoping to absorb the nutrients of traditional national music culture, reconstruct the "teacher-training mode" which adapts to and leads the music education and cultural heritage in the region. On the other hand, under the guidance and assistance of the contracted partner, the Institute of Music Education of the Central Conservatory of Music, we are committed to building a new music curriculum system, hoping to explore our own characteristics on this basis. Our ideal "new curriculum system" is a set of advanced music education practice system derived from the introduction of the three major international music education theories (Darcrotz music teaching method, Orff music teaching method, Kodaly music teaching method) and the combination of Chinese local music culture and educational reality. [1] Its core idea is to take students' mastery of systematic perceptual music experience as the basic teaching objective, the process of perceptual music activities as the main teaching content, the realization of independent emotional experience as the basic teaching requirements, the acquisition of inner music synesthesia as an important musical ability, and music practice as a significant teaching approach to promote. [2]

At present, there is only one undergraduate major in musicology (music education) in Chengdu Normal University. Compared with peer colleges, CNU has not established a perfect profession, and it has to make efforts to take into consideration to "platform" and "stage". As we know we can't do it and we have to do it, our talent training is bound to break through the existing practice, which mainly imitates the teaching organization form of professional art colleges. In other words, we can't simply compress and simplify the old way on the basis of the breadth and depth of courses in professional music colleges, but we must consolidate the two major standpoints of "higher education" and "profession" corresponding to the application-oriented transformation development proposed by schools, and then find out the specific links in the "industry chain" of basic education corresponding to this major to carry out teaching reform and curriculum reform, otherwise it will be difficult to obtain our own living space. We are consciously aware that different 
types and levels of schools should reflect the corresponding principles of differences in the way curriculum is organized. Professional music colleges are based on the logical system of disciplines, while application-oriented undergraduates should start from the professional-oriented post groups and their required professional abilities. Based on the analysis of the knowledge, ability and emotional elements required by the post, these elements should be corresponded to the knowledge points and application links in the disciplinary system. If possible, modularize them again, and form the applied professional curriculum in this way. Finally, the curriculum content arrangement with knowledge as logic is broken up, and the new curriculum teaching system with the core of knowledge application ability required by the post group is reassembled. [3]

The cooperation with the Institute of Music Education of the Central Conservatory of Music is facilitated in this context, and choosing it is mainly because of the recognition of their educational concepts. The undergraduate music education major of the Central Conservatory of Music advocates "let music belongs to every Chinese", and orientates the training of music education professionals as "from elite professional music education to popular school music education”. The specific approach is to transform the past solution of "basic knowledge and basic skills" into the so-called "new doublebase" education aiming at establishing basic musical emotional experience and basic musical activity experience. To be on the safe side, we adopt a more conservative reform mode of "coexistence of the old and the new, integration of the two systems", cancel the previous "solfeggio and ear training" and "basic music theory" courses, and build a new curriculum system of basic music education theory with the three main courses of "singing course", "chorus" and "rhythm". In addition, we retain other traditional courses, and ensure that the curricula of most of the original teachers remain unchanged. The new curriculum integrates the musical theory knowledge of the past clauses into the analysis and experience of musical works. It replaces the advanced fixed solfeggio exercises and the stylized dictation of intervals and chords with a large number of folk songs, nursery songs and nursery rhymes based on the culture of our mother tongue. The lyrics and language of these works are mainly based on dialects of different regions in China, and all of them are practiced by the first-tune singing method. The content of the reformed course strengthens the perception and training of chorus acoustics, adds the liberation training for body and mind and the nurturing of mother tongue culture, which are essentially different from the traditional courses. [4]

\section{EXPLORATION AND PRACTICE OF NEW CURRICULUM SYSTEM OF MUSICOLOGY}

In order to ensure the smooth implementation of the above work ideas, a new training team of music education curriculum has been set to participate in teaching reform in an all-round way. Meanwhile, the Institute of Music Education of the Central Conservatory of Music has given strong support. For example, they sent graduate students to CNU, and a team of instructors including their vice-president and foreign experts and professors to assist in our work. We have equipped our young and middle-aged backbone teachers for resident teaching staff and three basic theory backbone courses respectively to carry out comprehensive follow-up of "one-toone curriculum" and "one-to-one teacher" by means of joint discussion and cooperative development and on the basis of collecting and collating materials and information.

In order to change teachers' ideas to actively cooperate with the reform, CNU has sent teachers from the curriculum reform team to the Institute of Music Education of the Central Conservatory of Music every winter and summer vacation since 2014. Nevertheless, it is not easy to change the past thinking pattern and work inertia. At the beginning of the reform, some teachers and students did not know much about the new curriculum and could not adapt to it temporarily in terms of consciousness and concept, which caused some confusion and puzzlement. In view of the problems, we stipulate that teachers of professional basic skills courses, especially teachers of teaching method course team, should spend no less than 3 to 6 months in principle in the first-line follow-up study in primary and secondary schools every school year. On the one hand, this work idea comes from the reference to the training mode of the Institute of Music Education of the Central Conservatory of Music, the cooperative partner. When arranging the relationship between students' learning and practice, the five-year undergraduates usually study for two years in school, while the other time is basically complete in the music class of primary and secondary schools. On the other hand, it also benefits from the help of a series of incentive and restraint mechanisms in strengthening the construction of normal undergraduate majors in recent two years. Without strong support from the school level, this work is also difficult to promote.

The advantage of keeping the teachers of curriculum reform team on the front line of primary and secondary education for a long time is that they can understand and recognize the operation mechanism of music education in the schools and its related matters in their own professional fields as much as possible. For a long time, the environment will imperceptibly change a person. The desired results will come naturally, which is a kind of facts speak louder than words. Teachers will consciously and unconsciously discuss and analyze the professional abilities needed by the post groups in various teaching and research activities, then decompose and transfer these abilities into knowledge modules and finally form its own teaching ideas and direction of reform. At this time, we will lose no time to "invite" excellent teachers and researchers in primary and secondary schools to act as our students' teaching practice instructors, create a more favorable environment for public opinion to guide our curriculum reform to be opened according to post requirements, hence breaking the most difficult obstacles in the process of "application-oriented transformation". At the same time, it is also the "stubborn point" of the most difficult concept renewal in our teaching reform work.

Over the years, our curriculum reform has been highly concerned and widely praised by educational authorities, internship schools and employers. The key primary and secondary schools in Chengdu, such as the primary school affiliated to Sichuan University, the elementary school affiliated to the University of Electronic Science and 
Technology of China and the Wenjiang Experimental School, have cooperated with our college one after another to become the practice base of "curriculum reform", providing resources and platform support for our teaching practice. Through the practice test and personal experience of "curriculum reform" report concert performances and educational internship practice, ideological problems of the majority of teachers and students have gradually been better solved. Now it can be said that they accept and like the teaching and learning of the new curriculum from the heart, and benefit a lot from it. At the same time, the "musicology curriculum reform" in our college has attracted much attention from experts, scholars and brotherly colleges at home and abroad. Over the years, many colleges and universities have come to our college to guide, exchange, study, and jointly explore the reform and development of the undergraduate music curriculum. At present, many young teachers in our institute are interested in the reform orientation of this course and are actively learning and participating in it. Now our institute has formed a relatively stable curriculum reform team, and the team is expected to continue to grow under the good situation of continuous work. With the continuous deepening of the experimental reform of the new curriculum and the gradual maturity of the teaching staff of our college, we also plan to develop music courses and supporting textbooks suitable for our college and local areas.

Through the reform and exploration in recent years, there are still some problems that need to be solved. Firstly, in the traditional curriculum system, the course "basic music theory" is offered for one year and the course "solfeggio and ear training" is offered for two years, while the current basic theoretical courses such as "singing course", "chorus" and "rhythm" have been changed to three years, and some of them have been changed from 2 class hours a week to 4 class hours a week, bringing a relatively large pressure on teachers and school-running conditions. Secondly, the new curriculum system has made great breakthroughs in the original textbooks, and it is difficult for our province, our university and especially our students to directly use the existing teaching resources of the Central Conservatory of Music. So how to organize and select the appropriate teaching materials, and even how to improve the construction of textbooks is also important realistic issues. In addition, the teaching activities of the new curriculum system put forward extremely high requirements for teachers' knowledge accumulation, experience ability and activity experience. How to train our own qualified teachers and form echelons as soon as possible is an urgent task to be completed.

\section{EXPloring the REFORM OF PERSONNEL TRAINING MODEL WITH CHARACTERISTICS BASED ON THE NEEDS OF TRANSITION}

Over the years, CNU has striven to clarify ideas, find the right entry point and the characteristics of running a school on the basis of curriculum reform. We plan to further improve the personnel training program, which acts as a fulcrum to cultivate applied talents in musicology. To achieve this goal, we must adhere to the qualitative and quantitative requirements of the personnel training program of the Undergraduate Professional Construction Committee of the Ministry of Education, and put the training orientation into the logic of curriculum construction. In the process of perfecting the training plan, we have absorbed the valuable opinions put forward by the evaluation experts of Office of Academic Degree in Sichuan in the past two years to guide the work of the university. Considering the inherent requirements of the state for the transformation and development of local undergraduate colleges and the undergraduate qualification evaluation index system of the Ministry of Education, we have followed the requirements put forward in the 13th Five-Year Plan, namely the school-running orientation and overall transformation targets of the social and economic development service in the plain economic region of Chengdu. At the same time, taking full account of the objective conditions of running schools and their majors, the "one center, four simultaneous actions" professional talent training model for undergraduate musicology in our institute is finally developed.

This model is designed to enable students to acquire the teaching practice ability and artistic practice ability at the same time, which is the ultimate goal. The so-called "one center" is centered on the relevant courses of music teaching methods, and "four simultaneous actions" is to combine the professional abilities of singing, chorus and conductor, instrumental music and dance. We plan to gradually transform the traditional vocal music and piano courses into the integrated model of playing and singing, combine the vocal music course with the small group singing course, transfer from the traditional piano course to the applied piano course, deeply integrate the instrumental music teaching with Orff teaching method, dance and music rhythm course, and let the practical teaching system, subject competition, innovation and entrepreneurship, and even the training of outstanding teachers of applied undergraduate majors can be organically docked in our music talent training program, so that students can truly acquire the necessary "three kinds of abilities” of music teachers in primary and secondary schools during school learning, namely teaching ability, the ability to guide students' practice and training, and the ability to undertake reform projects in primary education. In order to ensure the acquisition of students' third ability, we require teachers to do more scientific research around technical services for music teaching reform in primary and secondary schools, and to carry out "innovation and entrepreneurship" education for students as the primary carrier. [5]

\section{CONCLUSION}

On the basis of what we have done in the curriculum system exploration, we are full of nothing but anxiousness and insecurity. In addition to fully devoted to the undertaking, we have to inform ourselves of constant reviewing and judging. The call for "inviting in" and "getting out" is expected to introduce advanced theories and acquire materials and resources that are beneficial to us, aiming to form our own characteristics in aspects like "practice strengthening”, "music as the key link", and "people-orientation". It is believed that we can find a way to conduct curriculum reform for undergraduate music major if keeping unswerving in this journey. 


\section{REFERENCES}

[1] Meng Hui. Exploration on Talent Cultivation Mode of "Music Education's New System" in Central Conservatory of Music [J]. Explorations in Music: 2013, (3).(In Chinese)

[2] Gao Jianjin. The "New Double Base" of Music Education in Schools-One of the Theoretical Interpretation and Practice of the New System of Music Education in Schools [J]. People’s Music: 2013, (9). (In Chinese)
[3] Gao Jianjin. Teaching Objectives, Contents and Methods of Music New Education System in Schools [J]. People’s Music: 2014, (1). (In Chinese)

[4] Gao Jianjin. Let Primary and Secondary School Music Education Return to the Origin of Music [J]. People’s Music: 2015, (11). (In Chinese)

[5] An Bingbing. Application of Music Education System in Higher Music Education [J]. Explorations in Music: 2016, (4). (In Chinese) 